\title{
Prostate Specific Antigen and Prostate Volume; How They are Correlated in Patients with Benign Prostatic Hyperplasia
}

\author{
Muhammad Hammad Jasim Alajeely ${ }^{1}$, Duraid Taha Abdulkareem², \\ Waleed Nassar Jaffal ${ }^{3}$, Nafea Sami Enad Al-Esawi ${ }^{4}$, Ehab Jasim Mohammad ${ }^{5}$ \\ ${ }^{1}$ Lecturer/Clinical Biochemistry Department, College of Medicine, University of Anbar, Ramadi, Iraq, ${ }^{2}$ Lecturer/ \\ Surgery Department, College of Medicine, University of Anbar, Ramadi, Iraq, ${ }^{3}$ Asis. Professor/Department of \\ Surgery, College of Medicine, University of Anbar, Ramadi, Iraq, ${ }^{4}$ Asis. Professor. College of Medicine, University \\ of Anbar, Ramadi, Iraq, ${ }^{5}$ Prof. Dr. FEBU,,FICMS, MBChB, Consultant Urologist, Head of Department of Surgery, \\ College of Medicine, IbnSina University of Medical and Pharmaceutical Sciences, Baghdad, Iraq
}

\begin{abstract}
Background: Human prostate-specific antigen (PSA) is a glycoprotein with approximately $7 \%(\mathrm{wt} / \mathrm{wt})$ carbohydrate. The PSA assay, along with other diagnostic parameters, is considered the most useful early malignancy marker to confirm the diagnosis of prostate disease. Benign prostatic hyperplasia (BPH) and prostatic cancer are the most common prostate diseases.

Objecive: The study was designed to assess the diagnostic sensitivity of PSA with different prostate volume $(\mathrm{PV})$ in Iraqi men aged (40 to 88 ) to define better predictions for early detection of prostatic cancer.

Method: The subjects involved in this study were 119 consecutive male aged (40-88) years with BPH. Prostate volume (PV) (measured by transrectal ultrasound: TRUS) and PSA density (PD) data distribution were evaluated. Variables of the clinical and laboratory display were expressed as mean $\pm \mathrm{SD}$. ANOVA were used for the comparison of variables. Pearson correlation coefficients were calculated for the whole study.

Result: Mean ( \pm SD) age of the subjects included in this study was $63.23 \pm 11.12$ years $(\mathrm{p}<0.01)$. The PSA values in different age groups $(40-54,55-69,70+)$, were: $5.71 \pm 4.47,7.87 \pm 4.55$ and $10.22 \pm 7.26 \mathrm{ng} / \mathrm{mL}$ respectively. There was a significant increase between the second and third group $(\mathrm{P}<0.05)$, while there was a highly significant increase between the first and third age groups $(\mathrm{P}<0.01)$. The correlation between PV and tPSA was $(+0.305)$ based on the Pearson's correlation co efficient $(\mathrm{P}<0.01)$.

Conclusion: Increase in prostate volume is associated with increased serum PSA level. A PSA level depicts approximate prostate volume and may have clinical potential in the management of BPH patients where PSA and prostate volume were significantly correlated in $\mathrm{BPH}$ patients.
\end{abstract}

Keywords: Prostate-Specific Antigen (PSA), TotalPSA, Free PSA, prostate volume (PV), Prostate density (PD), Benign prostatic hyperplasia (BPH) and prostatic cancer.

\section{Introduction}

The prostate gland is an accessory sex organ located on the bladder neck. Its hypertrophy causes urinary symptoms of a static (hesitation, retention) and dynamic (emergency, dribbling) nature. The incidence of prostate damage increases with age $e^{(1)}$.

The prostate specific antigen (PSA) is an organ specific tumor marker, single polypeptide chain glycoprotein with 240 amino acid residues, (molecular weight: 26,496), which consists of four carbohydrate side chains with several disulfide bonds ${ }^{(2)}$.

The PSA assay, along with other diagnostic parameters (ultrasound, international prostate symptom score), is the most useful investigation in the early detection of malignancy of the prostate gland ${ }^{(3)}$. 
Benign prostatic hyperplasia $(\mathrm{BPH})$ and prostatic cancer are the most commonly diagnosed prostate pathologies ${ }^{(4-6)}$.

Different factors like age, prostate volume (PV) and serum prostate specific antigen (PSA) determine the natural course of prostatic disease and the course which has been well studied ${ }^{(7)(8)}$.

The aim of each type of screening is to improve early detection of certain disease, reduce mortality rate and to improve the quality of life. The mortality rate of Pca can be decreased, if the disease is diagnosed early when it is confined to one organ ${ }^{(9)}$.

PSA is available in several isoforms. Two main forms are currently being measured.The PSA which iscomplexed with $\alpha 1$-antichymotrypsin and the free or uncomplexed PSA(fPSA) ${ }^{(10)}$

Numerous studies have reported extensively on the importance of total PSA (tPSA) and fPSA as tumor markers in the assessment of $\mathrm{PCa}$ and also the patients at risk. ${ }^{(11-15)}$

With this context, the present study is carried out in order to assess the levels serum PSA (total and free) and its relation to PV in Iraqi men suffering from benign prostatic conditions (BPH) in different age groups. The study was designed to assess the sensitivity of PSA with different prostate volume (PV) in Iraqi men aged (40 to 88 ) to define better predictions for the early detection of prostatic cancer.

\section{Method}

A total of 140 consecutive male patients aged more than 40 years presented,with symptoms of lower urinary tract suggesting prostatic hyperplasia,to the Urology Department of AL-Ramadi Teaching Hospital and private urology clinics, Iraq, from July 2018 to April 2019. 21 (15\%) of them were diagnosed with prostatic cacerand so excluded \& the remaining 119 (85\%) had $\mathrm{BPH}$ and were enrolled in this study.

The BPH was diagnosed according to the results of clinical and laboratory data and prostate biopsy when it is indicated. The main indication for the evaluation was lower urinary tract symptoms (LUTS)
Aconsent form was obtained from all patients who were subsequently subjected to a systematic assessment, including their medical history for the duration of symptom and assessment of severity of their symptoms, duration of medical treatment, previous surgical intervention and for complicated systemic disease, thorough physical examination,digital rectal examination (DRE),focused neurological assessment, uroflowmetry and the estimation of the prostatic volume bytransrectal ultrasonography using the formula: (П/6) $\mathrm{x}$ height $\mathrm{x}$ width $\mathrm{x}$ length ${ }^{(16)}$.Prostate density (PD) was calculated by dividing the preoperative PSA value by the estimated prostate volume. ${ }^{(17)}$

In this study, blood was drawn by venipuncture from patients and bloodis leftto clot at the room temperature.

Isolation of the serum was done by centrifugation 1 to 2 hours after blood collection and analysed to determine the total and the free PSA levels using Tosoh AIA-600 and patientswith tPSAmore than $4 \mathrm{ngm} / \mathrm{ml}$ were underwent transrectal prostate biopsy to exclude prostatic cancer.

Patients with neuropathic bladder dysfunction, bladder stones, urinary tract infection, previous urinary tract surgery or medications especially the 5 alpha reductase inhibitors, any systemic hormonal treatment, diabetes mellitus and chronic kidney disease were excluded from this study.

Division of the patients in this study into 3 groups was done according to the age: those who are 40 to 54 years and those who are 55 to 69 years and those who are over 70 years.

The was approved by the ethical committee in the college of medicine.

\section{Results}

The mean age of the patients was $63.23 \pm 11.12$ years. The older age of the patients involved in this study was 88 years and minimum age was 40years. The highest PSA level obtained in this study was $26.86 \mathrm{ng} / \mathrm{ml}$ and minimum was $2.87 \mathrm{ng} / \mathrm{ml}$, though the mean PSA was $8.25 \pm 5.84 \mathrm{ng} / \mathrm{ml}(\mathrm{p}<0.01)$. Table-1. 
Table (1): Clinical parameters of patients with Benign prostatic Hyperplasia.

\begin{tabular}{|l|c|c|c|c|c|}
\hline Parameters & $\mathbf{4 0 - 5 4 y}$ & $\mathbf{5 5 - 6 9 y}$ & $\mathbf{7 0}+\mathbf{y}$ & Total & p-value \\
\hline Number of patients (\%) & $25(21.0)$ & $52(43.7)$ & $42(35.3)$ & $119(100)$ & \\
\hline Age, mean \pm SD & $48.64 \pm 3.83$ & $60.27 \pm 4.22$ & $75.57 \pm 5.31$ & $63.23 \pm 11.12$ & \\
\hline TRUS $/$ PV mean \pm SD & $33.99 \pm 17.04$ & $38.41 \pm 15.46$ & $35.84 \pm 10.64$ & $36.57 \pm 14.31$ & \\
\hline f-PSA, mean \pm SD & $1.35 \pm 1.28$ & $2.23 \pm 1.56$ & $2.60 \pm 2.21$ & $2.18 \pm 1.81$ & $p<0.05$ \\
\hline t-PSA, mean \pm SD & $5.71 \pm 4.47$ & $7.88 \pm 4.55$ & $10.22 \pm 7.26$ & $8.25 \pm 5.84$ & $p<0.01$ \\
\hline r-PSA, mean \pm SD & $24.47 \pm 17.82$ & $28.94 \pm 17.21$ & $23.73 \pm 9.88$ & $26.16 \pm 15.25$ & \\
\hline PD, mean \pm SD & $0.49 \pm 0.61$ & $0.79 \pm 1.94$ & $0.55 \pm 0.33$ & $0.64 \pm 1.32$ & \\
\hline
\end{tabular}

Abbreviations: TRUS/PV, transrectal ultrasound estimated prostate volume; f \& t-PSA, free \& totalprostate specific antigen; rPSA, PSA ratio (free/total; PD, Prostate density; SD, standard deviation

Statistical analysis was carried out by SPSS statistics (IBM Corp., New York, United States) version 23 program. The differences in numerical data (age, PV, PD and PSA) among different age groups were analyzed by One-way analysis of variance (ANOVA) test. Comparison of age with other variables such as prostate volume was done by Pearson correlation test. AP value of less than 0.05 was considered statistically significant.

The PSA values in different age groups $(40-54,55-$ $69,70+)$, were, respectively, $5.71 \pm 4.47,7.87 \pm 4.55$ and $10.22 \pm 7.26 \mathrm{ng} / \mathrm{mL}$. There was a significant difference between the second and third group $(\mathrm{P}<0.05)$, while there was a highly significant increase between the first and third age groups $(\mathrm{P}<0.01)$.

The correlation between PV and PSA is 0.305 based on the Pearson's correlation co efficient $(\mathrm{P}<0.01)$, Table-2.

Table (2): Pearson Correlations

\begin{tabular}{|l|c|c|c|c|c|}
\hline Parameters & PD & PV & rPSA & fPSA & tPSA \\
\hline Age & -0.050 & -0.008 & 0.031 & $0.295^{* *}$ & $0.321^{* *}$ \\
\hline tPSA & 0.090 & $0.305^{* *}$ & 0.022 & $0.770^{* *}$ & \\
\hline fPSA & 0.171 & $0.238^{* *}$ & $0.594 * *$ & & \\
\hline rPSA & $0.226^{*}$ & 0.064 & & & \\
\hline PV & $-0.410^{* *}$ & & & & \\
\hline
\end{tabular}

*The correlation is significant at the 0.05 level (2-tailed)., **The correlation is significant at the 0.01 level (2-tailed).

\section{Discussion}

Bladder obstruction due to an enlarged prostate is the main contributor to the pathophysiology of clinical $\mathrm{BPH}^{(18)}$. However, imaging modalities were used to estimate the size of the prostate. PSA is typically used as an additional assessment in BPH patients to determine which patient benefits from a prostatic biopsy.

The correlation between the serum PSA level and $\mathrm{PV}$, in Iraqi men with BPH proven by biopsy, was determined by this study. In this study, the mean PV was
(36.57 \pm 14.31$)$ and the mean PSA was $(8.25 \pm 5.84)$ while in study on determination of age specific range of PSA done by Hilan and Rifaat ${ }^{(19)}$ on healthy Iraqi men as a control reference value, the mean PAS was $(1.31 \pm 0.66)$. In comparison with the normal reference PSA range, the mean PSA in current study was increased. The cause for this higher mean PSA level may be due to larger mean PV in this study; as there is a significant correlation between PSA and PV (Pearson Correlations: 0.305 $\mathrm{p}<0.01)$, the increased mean PSA may be explained by this finding. 
Also, significant correlation was seen between the age and the PSA in this study (Pearson Correlations: 0.321 $\mathrm{p}<0.01)$. These results are comparable to that obtained among other ethnic groups as shown in table- 3 .

Table 3: Comparison of PSA and prostate volume in Study of BPH population (Iraqi men) and other ethnicities

\begin{tabular}{|c|c|c|c|c|c|}
\hline \multirow{3}{*}{ Ethnicity } & \multirow{3}{*}{ No. } & \multirow{3}{*}{$\begin{array}{c}\text { Age (years) } \\
\text { Mean (range) }\end{array}$} & PSA $(\mathrm{ng} / \mathrm{ml})$ Mean \pm SD & PV (ml) Mean \pm SD & Correlation \\
\hline & & & r Age vs PSA & r Age vs PV & r PSA vs PV \\
\hline & & & (p-value) & (p-value) & (p-value) \\
\hline \multirow{3}{*}{ Iraqi (Current study) } & \multirow{3}{*}{119} & \multirow{3}{*}{$63.23(40-88)$} & $8.25 \pm 5.84$ & $36.57 \pm 14.31$ & \\
\hline & & & 0.321 & NS & 0.305 \\
\hline & & & $(0.0001)$ & & $(0.001)$ \\
\hline \multirow{3}{*}{$\operatorname{Indian}(20)$} & \multirow{3}{*}{40} & \multirow{3}{*}{$64.1(46-84)$} & $2.3(0.28-8.76)$ & $43.0(23.8-143)$ & \\
\hline & & & 0.493 & 0.340 & 0.933 \\
\hline & & & $(0.001)$ & $(0.03)$ & $(0.001)$ \\
\hline \multirow{3}{*}{ Indian(21) } & \multirow{3}{*}{162} & \multirow{3}{*}{ NA (50-93) } & $17.85 \pm 13.80$ & $37.20 \pm 32.07$ & \\
\hline & & & 0.445 & NS & 0.59 \\
\hline & & & $(0.05)$ & & $(0.001)$ \\
\hline \multirow{3}{*}{ Saudi(22) } & \multirow{3}{*}{447} & \multirow{3}{*}{$64.2(20-89)$} & $2.2 \pm 1.5$ & $35.2 \pm 22.5$ & \\
\hline & & & 0.324 & 0.306 & 0.441 \\
\hline & & & $(0.0001)$ & $(0.001)$ & $(0.0001)$ \\
\hline \multirow{3}{*}{$\begin{array}{l}\text { White (European) } \\
\text { (23) }\end{array}$} & \multirow{3}{*}{354} & \multirow{3}{*}{$70.2(45-91)$} & $3.9 \pm 4.2$ & $40.1 \pm 23.9$ & \\
\hline & & & 0.28 & 0.25 & 0.54 \\
\hline & & & $(0.0001)$ & $(0.0001)$ & $(0.0001)$ \\
\hline \multirow{3}{*}{ Nigerian(24) } & \multirow{3}{*}{120} & \multirow{3}{*}{$65.6(45-85)$} & $12.44 \pm 15.49$ & $72.79 \pm 44.38$ & \\
\hline & & & 0.026 & NS & 0.337 \\
\hline & & & $(0.05)$ & & $(0.05)$ \\
\hline \multirow{3}{*}{ Indonesian(25) } & \multirow{3}{*}{1638} & \multirow{3}{*}{$65.67(40-92)$} & $4.78 \pm 2.74$ & $43.93 \pm 21.08$ & \\
\hline & & & 0.07 & 0.12 & 0.26 \\
\hline & & & $(0.008)$ & $(0.0001)$ & $(0.0001)$ \\
\hline
\end{tabular}

No.: Number of patients, NS: not significant, NA: not available.

The age of the BPH patients did not correlate with the PV and was not significant. In this study, PV did not increase or decrease in the different age groups. Selection bias may be the cause for this difference. There was unequal distribution of the patients in this study among the study goups with about $21 \%$ of patients lie in the 40-50 year old age group and this unequal distribution may explain the statistical analysis difference. If we had recruited younger patients, the correlation between the age and PV might have been significant. This conclusion is in line with what Duvedietal does observed in their study of Indian men ${ }^{(21)}$ and Udeh et al. of Nigerian $\operatorname{men}^{(24)}$.

A significant correlation was seen between PV and PSA density (PD) $(r=0.410$, p-value $<0.001)$ in $\mathrm{BPH}$ patients. This finding also agreed with what Duvedi et al.does observed in their study of Indian men ${ }^{(21)}$.

In our study, no correlation was observed between PD or PV vs advancing age in BPH patients, but Serum PSA was found to be significantly correlated with PV. Therefore, before interpreting PSA values, prostate volume should be taken into consideration in order to get rid of the undue prostatic biopsies depending on the level of PSA alone.

Limitation: Further studies with larger sample size and age-matched control group are required to validate our findings and to maximize the diagnostic accuracy of PSA while testing the relationship between PV, PSA density and patient age. 


\section{Conclusion}

The age of patients with BPH was correlated with PSA levels (free \& total). Therefore the age of the patients should be taken into consideration while interpreting PSA levels. PV and PD did not increase or decrease with age in this study. PSA and prostate volume were significantly correlated in BPH patients. Increase in prostate volume is associated with increased serum PSA level. PSA levels depicts approximate prostate volume and may have clinical potential in the management of patients with BPH.

Ethical Clearance: The Research Ethical Committee at scientific research by ethical approval of both MOH and MOHSER in Iraq.

\section{Conflict of Interest: Non}

Funding: Self-funding

\section{References}

1. Banerjee B, Iqbal BM, Kumar H, Kambale $\mathrm{T}$, Bavikar R. Correlation between prostate specific antigen levels and various prostatic pathologies. JMS - J Med Soc. 2016;30(3):172-5.

2. Watt KWK, Lee PJ, M'Timkulu T, Chan WP, Loor R. Human prostate-specific antigen: Structural and functional similarity with serine proteases. Proc Natl Acad Sci U S A. 1986;83(10):3166-70.

3. Polascik TJ, Oesterling JE, Partin AW. Prostate specific antigen: a decade of discovery-what we have learned and where we are going. J Urol. 1999;162(2):293-306.

4. Lepor H. Pathophysiology, epidemiology and natural history of benign prostatic hyperplasia. Rev Urol. 2004;6(Suppl 9):S3.

5. Al-Khalil S, Ibilibor C, Cammack JT, de Riese W. Association of prostate volume with incidence and aggressiveness of prostate cancer. Res Reports Urol. 2016;8:201-5.

6. Al-Khalil S, Boothe D, Durdin T, Sunkara S, Watkins P, Yang S, et al. Interactions between benign prostatic hyperplasia $(\mathrm{BPH})$ and prostate cancer in large prostates: a retrospective data review. Int Urol Nephrol. 2016;48(1):91-7.

7. Oesterling JE, Kumamoto $\mathrm{Y}$, Tsukamoto $\mathrm{T}$, Girman CJ, Guess HA, Masumori N, et al. Serum prostate-specific antigen in a community-based population of healthy Japanese men: lower values than for similarly aged white men. $\mathrm{Br} \mathrm{J}$ Urol. 1995;75(3):347-53.

8. Kim JS, Ryu J-G, Kim JW, Hwang EC, Jung S Il, Kang TW, et al. Prostate-Specific Antigen fluctuation: what does it mean in diagnosis of prostate cancer? Int braz j urol. 2015;41(2):258-64.

9. Azab S, Osama A, Rafaat M. Does normalizing PSA after successful treatment of chronic prostatitis with high PSA value exclude prostatic biopsy? Transl Androl Urol. 2012;1(3):148.

10. Jemal A, Siegel R, Ward E, Murray T, Xu J, Smigal C, et al. Cancer statistics, 2006. CA Cancer J Clin. 2006;56(2):106-30.

11. Stamey TA, Yang N, Hay AR, McNeal JE, Freiha FS, Redwine E. Prostate-specific antigen as a serum marker for adenocarcinoma of the prostate. N Engl J Med. 1987;317(15):909-16.

12. Labrie F, Dupont A, Suburu R, Cusan L, Tremblay M, Gomez J-L, et al. Serum prostate specific antigen as pre-screening test for prostate cancer. J Urol. 1992;147(3 Part 2):846-51.

13. Brawer MK, Chetner MP, Beatie J, Buchner DM, Vessella RL, Lange PH. Screening for prostatic carcinoma with prostate specific antigen. J Urol. 1992;147(3 Part 2):841-5.

14. Sawyer R, Berman JJ, Borkowski A, Moore GW. Elevated prostate-specific antigen levels in black men and white men. Mod Pathol an Off J United States Can Acad Pathol Inc. 1996;9(11):1029-32.

15. Seabury CA, Calenoff E, Ditlow C, Bux S, Clarke $\mathrm{H}$, Issa $\mathrm{M}$, et al. Evaluation of a new serum testing method for detection of prostate cancer. J Urol. 2002;168(1):93-9.

16. Wolff JM, Boeckmann W, Mattelaer P, Handt S, Adam G, Jakse G. Determination of prostate gland volume by transrectal ultrasound: correlation with radical prostatectomy specimens. Eur Urol. 1995;28:10-2.

17. Murciano-Goroff YR, Wolfsberger LD, Parekh A, Fennessy FM, Tuncali K, Orio PF, et al. Variability in MRI vs. ultrasound measures of prostate volume and its impact on treatment recommendations for favorable-risk prostate cancer patients: A case series. Radiat Oncol. 2014;9(1):1-6.

18. Shapiro E, Lepor H. Pathophysiology of clinical benign prostatic hyperplasia. Urol Clin North Am. 1995;22(2):285-90. 
19. Hailan M, Rifat UN. Age-specific reference ranges of serum prostate-specific antigen in Iraqi men. Arab J Urol [Internet]. 2011;9(4):273-7. Available from: http://dx.doi.org/10.1016/j.aju.2011.09.005

20. Deori R, Das B, Rahman MA. A Study of Relationship of Prostate Volume, Prostate Specific Antigen and age in Benign Prostatic Hyperplasia. Int J Contemp Med Res. 2017;4(7):1582-6.

21. Duvedi P, Singh H, Bedi GK, Kaur M. Role of Prostate-Specific Antigen (PSA) in Patients with Benign Prostate Hyperplasia. J Clin Diagnostic Res. 2019;15-7.

22. Mosli HA, Abdel-Meguid TA-A. The relationship between prostate volume, prostate-specific antigen and age in Saudi men with benign prostatic conditions. African J Urol. 2010;16(4):117-23.
23. Vesely S, Knutson T, Damber J-E, Dicuio M, Dahlstrand C. Relationship between age, prostate volume, prostate-specific antigen, symptom score and uroflowmetry in men with lower urinary tract symptoms. Scand J Urol Nephrol. 2003;37(4):322-8.

24. Udeh E, Dakum N, Amu O, Ramyl V. Correlation between serum prostate specific antigen and prostate volume in Nigerian men with biopsy proven benign prostatic hyperplasia: prospective study. Int J Urol. 2009;7(2).

25. Putra IBOW, Hamid ARAH, Mochtar CA, Umbas R. Relationship of age, prostate-specific antigen and prostate volume in Indonesian men with benign prostatic hyperplasia. Prostate Int [Internet]. 2016;4(2):43-8. Available from: http://dx.doi. org/10.1016/j.prnil.2016.03.002 